\title{
Reflexivization and Reciprocality in the Kalahari Language
}

\author{
Jackrich Oribomate * \\ (University of Nigeria, Nigeria) \\ Sopuruchi Christian Aboh ** \\ (University of Nigeria, Nigeria)
}

\begin{abstract}
This paper examines reflexivization and reciprocality in Kalabari with particular attention to the forms, functions and structures of reflexive and reciprocal constructions (the nominal sub-type) in the language. The paper adopts the binding theory as a framework in analysing the data. The data were gathered through interaction and introspection. The findings reveal that reflexives and reciprocals in Kalabari require a compatible clause-mate antecedent due to the strong anaphoric relationship between reflexive and reciprocal markers and their antecedents respectively. The findings further reveal that the form of Kalabari reflexives consists of - $\underline{b} \grave{u}$ (-self) and the appropriate form of the pronoun in the language. The paper also reveals that the Kalabari language makes a tripartite distinction for number, person and gender, and the form of the reflexive does not change; only the pronoun changes, while reciprocals consist of a reduplicated form jumo jumo, jápu jápu and jéin jéin. In terms of the structure, findings reveal that reflexives and reciprocals come before the verb of the clause in which they occur. The finding further reveals that reflexives in the language perform both non-emphatic and emphatic functions, while reciprocal relates to human and non-human reference of mutuality. Tonal inflection also makes a distinction in 1 st person singular and 2 nd person singular reflexives. It is therefore recommended that more studies be done to ascertain the form, function and structure of the verbal and possessive sub-type of reflexive and reciprocal constructions in the language.
\end{abstract}

Keywords: reflexives, reciprocals, binding, Kalabari, Universal Grammar

\section{Introduction}

Reflexivization can be defined as the process of converting a noun or its equivalent into

\footnotetext{
* Jackrich Oribomate: Department of Linguistics, Igbo and Other Nigerian Languages, University of Nigeria, Nigeria. E-mail: jackrichoribomate@gmail.com.

** Sopuruchi Christian Aboh: Assistant Lecturer, Department of Linguistics, Igbo and Other Nigerian Languages, University of Nigeria, Nsukka, University of Nigeria, Nigeria. E-mail: sopuruchi.aboh@unn. edu.ng.
} 
a reflexive pronoun. Meanwhile, reflexive pronouns like personal pronouns refer to people or things that have previously been mentioned in the same sentence that they occur. On the other hand, reciprocality is the expression of mutuality. This mutuality can be expressed by means of reciprocal pronouns. In other words, reciprocal pronouns are pronouns which express the meaning of mutual relationship (cf. Nwosu, 2006; Okeke, 2008).

The study of reflexivization and reciprocality has in recent times generated much interest among scholars, especially within the framework of Government and Binding. Government and Binding (GB) is a classical Chomskyan model of grammar which gives an insight that language is a relationship between sounds and meanings (Chomsky, 1981). Although some studies have been done on the topic in Igbo (Uchechukwu, 2006; Okeke, 2008, 2015), Arabic (Al-Raba'a, 2017), Akan (Saah, 2018), Japanese (Nishigauchi, 2017), Ga (Otoo, 2016), Ewe (Larnyo \& Glover-Meni, 2019), it appears that the study of reflexivization and reciprocality in the Kalabari language has received little or no attention, to the best of the researchers' knowledge. This could be because the Kalabari language has not been subjected to rigorous linguistic investigation in the area of syntax to provide relevant literature in the language. It is against this background that this paper examines and describes reflexives and reciprocals in the Kalabari language with a view to ascertaining the forms, functions and structures of Kalabari reflexive and reciprocal constructions. Due to the unavailability of materials, however, the researchers resorted to interactive discourse in everyday use of the language and introspection in gathering the data for this study. The data are analysed by drawing insights from binding theory.

This paper therefore focuses on the nominal sub-type of the construction and not the verbal or possessive sub-type. It is, therefore, hoped that this work will form part of the written records of the Kalabari syntax and make a significant contribution to knowledge by complementing available literature on the subject matter in other languages and also serve as a reference for researchers and scholars alike. Kalabari language is a member of the Eastern Ijo language cluster, which is one of the four sub-groups (defined on the basis of shared innovations), others being Nembe (with Akasa), Oruma-oko-dia-Biseni and Izon.

\section{Theoretical foundations}

One of the theoretical approaches to the study of reflexivization is binding theory under Universal Grammar (UG). UG is a classical model of grammar, which helps to determine the common properties of the languages of the world and reduce same to a minimum of rules, such that these rules will be used to account for the natural languages used by man in his immediate environment (cf. Chomsky, 1981). Universal Grammar proposed two major properties of language, namely, principles and parameters. Principles are potential universal attributes of natural languages or the properties of grammatical operations, while 


\section{Jackrich Oribomate \& Sopuruchi Christian Aboh}

parameters refer to the dimensions of grammatical variations among natural languages (cf. Ndimele, 2004). This implies that principles are those properties commonly shared by all languages of the world, while parameters are parametric variations (differences) that are particular to each language. The principle that applies to this study is binding theory.

This paper adopts the binding theory, because of the strong anaphoric relationship between anaphors and their antecedents. Binding theory was proposed by Chomsky (1981) in his book entitled Lectures on Government and Binding. The main ideas behind binding theory as proposed by Chomsky (1981) are to: characterize the anaphoric or interpretive relations between different NPs in a sentence, and determine the distribution of reflexives, reciprocals, pronominals, and overt NPs.

Simply put, binding theory tries to find out if in a given linguistic expression containing more than one NP, a given NP can be interpreted as co-referential to another (cf. Mbah, 2011). Anaphor is an NP, which can have no independent reference, but which takes its reference from some other expression in the sentence, its antecedent (Radford, 1981). Meanwhile, a reflexive pronoun is an anaphoric pronoun which bears the action performed by its antecedent; while a reciprocal pronoun is the pronoun which usually occurs in co-ordinated form and which exchanges action performed by each on the other (cf. Mbah, 2011).

\section{Analysis and discussion}

In this section, a presentation of data from the Kalabari language is made and analysed.

\subsection{Forms of reflexives and reciprocal in Kalabari}

In this sub-section of the work, data shall be presented on reflexives in the language.

Examples:

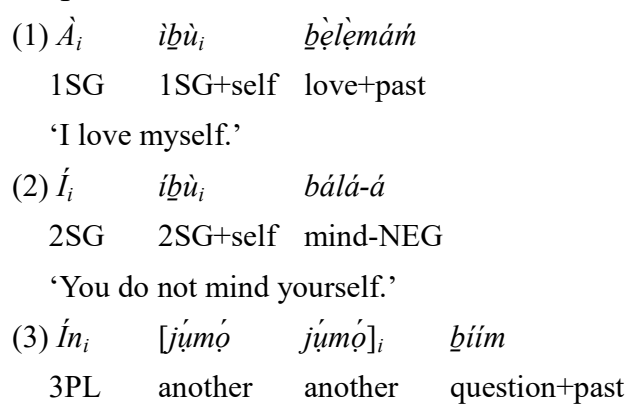

'They questioned each other.'

$\begin{array}{clllllll}\text { (4) }[\text { Bòmá } & n a ̀ & \text { Ńgó } & n a ̀]_{i} & \text { in } & \text { [jưmọ } & \text { jụmọ́ }]_{i} & \text { bẹlẹmám } \\ \text { Boma } & \text { CONJ } & \text { Ngo } & \text { CONJ } & \text { 3PL } & \text { another } & \text { another } & \text { love+past }\end{array}$

'Boma and Ngo loved each other.'

In the examples above, all reflexives and reciprocals belong to the same minimum clause, 
and are co-indexed with their antecedents. While (1) and (2) show reflexives in the first and second person respectively, (3) and (4) show the form of reciprocal in the language. Tone serves to distinguish between the first person singular and the second person singular. The tone on the former is low, while that of the latter is high. One striking feature of Kalabari reflexives and reciprocals in the above examples is that they occur after the nominal elements before the predicate or verbal complex. This is in sharp contrast with what is obtainable in English where the reflexives come after the verb. This positioning concurs with Rooryck and Wyngaerd's (2011:14) submission that “...correct insertion of reflexive and nonreflexive pronouns requires that the context of insertion has to be able to read off the syntax what is and what is not a reflexive environment". This then concurs with the rule of principles and parameters in Universal Grammar, which states that languages may have certain features in common (principles) but the way of realising such features may differ (parameters).

In the Mbaise dialect of Igbo, Nwosu (2005) observes that antecedent-anaphor relations hold in the dialect and that onwe 'self', ibe 'self' and ogwe 'self' are all anaphors. The study also shows that while some anaphors are bound in the minimal domain, others cross clause boundaries. It further reveals that antecedents of anaphors must not always be subjects in the dialect, especially when used idiomatically.

The issue of whether reflexives are really a case of binding or inclusiveness condition under Minimalist Programme has been debated in literature. As argued by Chomsky (1981), the agreement or co-indexation between the anaphor and its antecedent is based on the principle of binding. This position was later criticised by Chomsky (1995) under the Inclusiveness Condition which is one of the conditions in Minimalism, which states that syntactic constructions do not bring in extra-features outside the ones already present in the lexical items that made up the constructions. However, Rooryck and Wyngaerd (2011) propose that the relationship between agreement and anaphoric dependencies is a case of Binding relationship because even within Minimalism, agreement follows from the relationship established by Agree.

\subsection{Functions of reflexives and reciprocals in Kalabari}

Reflexives perform basically two functions in Kalabari as in English: the emphatic and non-emphatic functions. Below are examples to illustrate the functions they perform.

\subsubsection{Non-emphatic function}

Examples (1)-(4) are all examples of non-emphatic functions of reflexive in the language. Below are examples of emphatic functions.

\subsubsection{Emphatic function}

$\begin{array}{rllll}\text { (5) İbièné } & \underline{\text { bránà }} & \text { óbírí } & \underline{\text { bè }} & \text { báám } \\ \text { Íbíene } & \text { by hand/self } & \operatorname{dog} & \text { ART } & \text { kill+past }\end{array}$




\section{Jackrich Oribomate \& Sopuruchi Christian Aboh}

'Íbíene herself killed the dog.'
(6) $B$ òmá
bránà
ób $\grave{u}_{i} \quad \underline{b a ́ a ́ m}$
Boma
byhand/self
3SG+self kill+past
'Boma (himself) killed himself.'

With the examples above, one can easily distinguish between the emphatic and non-emphatic functions of reflexives in the Kalabari language. The word brána is used to introduce or indicate an emphatic function in the language. However, brána is used alone and does not require the $3 \mathrm{sg}$ reflexive when the action denoted by the verb of the sentence is transferred to an object as in (5). On the other hand, if the subject is the same entity that suffers the action denoted by the verb, then brána and the 3sg reflexive óbù as in (6) will be used to show this difference. The reflexives in the Kalabari language assume a different structure to perform either non-emphatic or emphatic functions. The first is the addition of $-\underline{b} \dot{u}$ to the appropriate form of the pronoun in the language, as in the examples from (1)-(4), while the second structure is the use of - $\underline{b} \grave{u}$ plus the appropriate form of the pronoun together with the emphatic form brána as in (5) and (6).

Note here that, examples (5) and (6) are cases of gender. While the former is used to show the feminine gender, the latter is used to show the masculine.

3.2.3 Functions of reciprocals

Examples:

$\begin{array}{rlll}\text { (7) } \dot{I n}_{i} & \text { [jưmó } & \text { jưmó }]_{i} & \text { biim } \\ \text { 3PL } & \text { another } & \text { another } & \text { question+past }\end{array}$

'They questioned each other.'

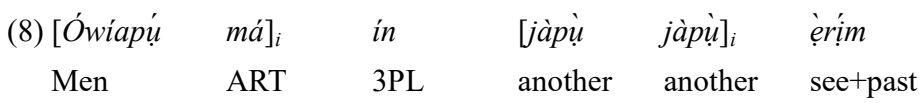

'The men saw one another.'

(9) Obiri $m a_{i} \quad$ [jéin $\quad$ jéin $]_{i}$ ónwín

dog ART another another bite

'The dogs bit each other/one another.'

From the above examples, the reciprocals belong to the same clause that their antecedents are, and are co-indexed with their antecedents. Examples (7) and (8) make mutual human reference for two and more than two persons respectively, while (9) makes a non-human reference of mutuality. Whereas Kalabari reciprocals are gender-sensitive, those in Igbo are not (Okeke, 2008).

\subsubsection{Structures of reflexives and reciprocals in Kalabari}

\section{Reflexives}

$\begin{array}{rlll}\text { (10) } \dot{I n}_{i} & {[j u ̛ m o ̣} & \text { jưmóo }]_{i} & \text { biim } \\ \text { 3PL } & \text { another } & \text { another } & \text { question+past }\end{array}$


Reflexivization and Reciprocality in the Kalabari Language

'They questioned each other.'

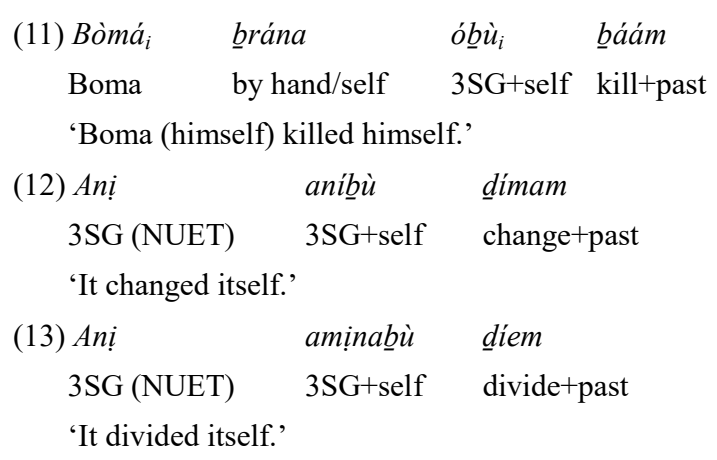

\section{Reciprocals}
(14) Òbìri $m a_{i} \quad$ [jéin jéin $]_{i}$ ónwín
$\operatorname{dog}$ ART another another bite

'The dogs bit each other/one another.'

$\begin{array}{cllllllll}\text { (15) }[\text { Bòmá, } & n a ̀ & \text { Ńgó } & n a ̀ & \text { Bọ́bọ } & n a ́]_{i} & {[j a ́ p u} & \text { jápu }]_{i} & \text { ẹrịim } \\ \text { Boma } & \text { CONJ } & \text { Ngo } & \text { CONJ } & \text { Bobo } & \text { CONJ } & \text { another } & \text { another } & \text { see+past }\end{array}$

'Boma, Ngo and Bobo saw one another.'

Based on the three binding conditions proposed in Government and Binding, which state that: (a) an anaphor is bound in its local domain: this means that all reflexives must be properly bound to their antecedents; (b) a pronominal is free in a local domain: this means that every pronoun is free in the minimal clause containing it; and (c) a referring expression is free: this means that all referential experiences (entities called by name) are free (Ndimele, 2004; Mbah, 2011; Agbedo, 2015). It can be said the reflexives and reciprocals above abided by the first condition because they properly bound to their antecedents.

With the above examples from (10)-(15), it is indicated that the structure for reflexives and reciprocals in the minimal clause in which they occur is SOV (i.e. the object, which is the reflexive or reciprocal occurs after the subject but before the verb). Note that (12) and (13) are examples of neuter gender in the language. The forms aníbù/aminabù can be used interchangeably. The examples are anaphoric because the reflexives and reciprocals have antecedents. More so, the referencing feature is that of endo-spatiality where what is being referred to is within the participation space. As can be seen in (10), (14) and (15), the entities that performed the reflexive or reciprocal actions are within the same space where the actions were performed. As observed in literature, in some languages like Igbo, outside any definite context, a plural situation in the Igbo language could refer to reflexives or reciprocals, i.e., both reflexives and reciprocals are marked by the same plural markers in the language. Igbo reflexive construction comprises the nominal onwe and a personal pronoun, both of which give rise to the structure (onwe + pronoun). 
Another significant feature of reflexivization and reciprocality in Kalabari is that it is only verbs, which can take both subject and object that can be reflexivised and reciprocalised. More so, there is no case of inherent reflexive or reciprocal structures in Kalabari. The structure of Kalabari reciprocals is that of reduplicated anaphor: jéin jéin and jápu jápu. This feature of reduplicated reciprocal is observable in Ewe, a Ghanaian language where the reduplicated quantifier nkornkor performs the function of reciprocality (Saah, 2018).

Table 1. Forms of reflexives in the Kalabari language

\begin{tabular}{|c|c|c|c|c|c|}
\hline \multirow{2}{*}{ PERSON } & \multicolumn{2}{|c|}{ NUMBER } & \multicolumn{3}{|c|}{ GENDER } \\
\hline & Singular & Plural & Masculine & Feminine & Neuter \\
\hline 1 st person & $i \underline{b u ̀}$ & waminabù̀ & & & \multirow{3}{*}{ aníbùu/amịnabù } \\
\hline 2nd person & $i \underline{b u} u$ & ominabùu & & & \\
\hline 3rd person & óbùúábù & ínabù & $o \underline{b u ̀ u}$ & $a ́ b \underline{u}$ & \\
\hline
\end{tabular}

The table shows the different forms of the Kalabari reflexives. Note that like English and other languages, the 1st and 2nd person are not marked for gender but unlike Igbo, Kalabari marks gender for the 3rd person as in English. It is also important to note that the neuter form is not marked for plural. Only the singular form is marked in the language and both forms aníbù/amịnabù can be used interchangeably.

\section{Conclusion}

This study empirically proves that reflexivization and reciprocality abound in the Kalabari language. From the analysis, it is revealed that reflexives and reciprocals in the language require a compatible clause-mate antecedent due to the strong anaphoric relations between reflexive and reciprocal markers and their antecedents respectively. Findings also reveal that the form of Kalabari reflexives consists of - $\underline{b} \grave{u}$ '-self' and the appropriate form of the pronoun in the language. It is also observed that the Kalabari language makes a tripartite distinction for number, person and gender, i.e., while pronouns are marked for number, person and gender, the form of the reflexive does not change; only the NP changes its form to indicate a change in gender. Reciprocals, however, consist of a reduplicated form jumo jumo, jápu jápu and jéin jéin. It was also discovered that reflexives in the language perform both non-emphatic and emphatic functions, while reciprocal relates to human and non-human reference of mutuality. Lastly, that reflexives and reciprocals come before the verb of the clause in which they occur structurally. Tone also plays a role in distinguishing between the first person singular and the second person singular.

There are some examples of reflexive and reciprocal constructions in the Kalabari language. The Kalabari reflexives and reciprocals belong to the same minimal clause as 
their antecedents. The form of the reflexive consists of - $\underline{b} \grave{u}$ '-self' and the appropriate form of the pronoun in the language, while the reciprocals are reduplicated forms. Reflexives and reciprocals come after the subject but before the verb of the clause in which they occur structurally. Reflexives in the language perform both non-emphatic and emphatic functions, while the function of reciprocals is to make human and non-human reference of mutuality.

Sequel to the objectives and findings of this study which is restricted only to the nominal sub-type of reflexive and reciprocal constructions, it is therefore recommended that more studies be done to ascertain the form, function and structure of verbal and possessive sub-types of reflexive and reciprocal construction in the language.

\begin{tabular}{llll}
\multicolumn{2}{l}{ Abbreviations } & & \\
1 & First Person & NEG & Negation \\
2 & Second Person & NUET & Neuter \\
3 & Third Person & PL & Plural \\
ART & Article & SG & Singular \\
CONJ & Conjunction & &
\end{tabular}

\section{References}

Agbedo, C. 2015. General Linguistics: Historical and contemporary perspectives [M]. Nsukka: KUMCEE -Ntaeshe Press Inc.

Al-Raba'a, B. I. 2017. Reflexivity and Reciprocality in Arabic [D]. PhD Dissertation. Bloomington: Indiana University.

Chomsky, N. 1981. Lectures on Government and Binding [M]. Dordrecht: Foris Publications.

Chomsky, N. 1995. The Minimalist Program [M]. Massachusetts: The MIT Press.

Laryno, P. K. \& N. Glover-Meni. 2019. Causality Related to Coreferential and Reciprocal Structures in Ewe [J]. Journal of Language and Linguistic Studies, 15(3):1188-1203.

Mbah, B. M. 2011. GB Syntax: A minimalist theory and application to Igbo [M]. Enugu: CIDJAP Press.

Ndimele, O. 2004. Principles and Parameters of Universal Grammar: A government-binding [M]. Owerri: Educational Services.

Nishigauchi, T. 2017. Syntax of Reciprocals in Japanese [J]. Journal of East Asian Linguistics, 1(2):157196.

Nwosu, C. 2006. Antecedent-Anaphor Relations in Mbaise Dialect of Igbo [D]. MA Thesis. Nsukka: University of Nigeria.

Okeke, C. O. 2008. Reflexivization and Reciprocality in Igbo [J]. Journal of the Linguistic Association of Nigeria, 11:185-197.

Okeke, C. O. 2015. Reflexive and Reciprocal Verbs in Igbo [J]. Igbo Language Studies, 1:87-104.

Otoo, R. 2016. Reflexives and Reciprocal Relations in Ga [J]. Advances in Social Sciences Research Journal, 3(11):141-153.

Radford, A. 1981. Transformational Syntax [M]. Cambridge: Cambridge University Press.

Rooryck, J. \& G. V. Wyngaerd. 2011. Dissolving Binding Theory [M]. Oxford: Oxford University Press.

Saah, K. K. 2018. The syntax of Reciprocal Constructions in Akan [J]. Ghana Journal of Linguistics, 7(2):52-70.

Uchechukwu, C. 2006. The Reflexive-Reciprocal Polysemy in Igbo [D]. MA Thesis. Nsukka: University of Nigeria. 